\title{
CARACTERIZAÇÃO QUÍMICA E ESPECTROSCÓPICA DE ÁCIDOS HÚMICOS E FÚLVICOS ISOLADOS DA CAMADA SUPERFICIAL DE LATOSSOLOS BRASILEIROS ${ }^{(1)}$
}

\author{
Leonardo Barros Dobbss ${ }^{(2)}$, Victor Marcos Rumjaneck ${ }^{(3)}$, Marihus Altoé \\ Baldotto $^{(4)}$, Ary Carlos Xavier Velloso ${ }^{(5)}$ \& Luciano Pasqualoto Canellas ${ }^{(6)}$
}

\begin{abstract}
RESUMO
A determinação de características estruturais das substâncias húmicas (SH) é essencial para o entendimento do comportamento da química de superfície dos solos altamente intemperizados. Ácidos húmicos (AH) e fúlvicos (AF) obtidos no horizonte superficial de sete Latossolos de diferentes regiões do Brasil foram caracterizados mediante a análise da composição elementar, da acidez total e carboxílica, da capacidade de oxidação e por métodos espectroscópicos. As substâncias húmicas apresentaram elevado grau de oxidação, acidez e massa molecular relativamente baixas, caracterizando a matéria orgânica alcalina solúvel como bastante reativa. Os $\mathrm{AF}$ apresentaram menor teor de $\mathrm{C}$ e maior de $\mathrm{O}$ do que os AH. Foram observados valores elevados da relação entre absorvância em 465 e $665 \mathrm{~nm}\left(\mathrm{E}_{4} / \mathrm{E}_{6}\right)$ e a massa molar média foi estimada em 1.106 e $618 \mathrm{~g} \mathrm{~mol}^{-1}$ para $\mathrm{AH}$ e AF, respectivamente. A menor massa molar estimada para os AF foi compativel com sua menor complexidade química revelada pelos espectros de IV-TF, que apresentaram menor número de bandas de absorção bem definidas. A ressonância magnética nuclear $\left(\mathrm{RMN}^{1} \mathrm{H}\right)$ mostrou a presença de $\mathrm{H}$ mais hidrofóbico nos $\mathrm{AH}$ e de $\mathrm{H}$ ligado a átomos de $\mathrm{O}$ em maior quantidade nos $\mathrm{AF}$, compatível com sua maior acidez e, portanto, solubilidade em qualquer valor de $\mathrm{pH}$. Apesar da mesma funcionalidade química encontrada tanto nos $\mathrm{AH}$ como nos $\mathrm{AF}$, a análise estatística
\end{abstract}

\footnotetext{
(1) Parte da Tese de Mestrado do primeiro autor, apresentada à Universidade Estadual do Norte Fluminense - UENF. Recebido para publicação em julho de 2008 e aprovado em dezembro de 2008.

${ }^{(2)}$ Doutorando do Programa de Pós-graduação em Produção Vegetal - Laboratório de Solos, Universidade Estadual do Norte Fluminense - UENF. Av. Alberto Lamego 2000, Parque Califórnia, CEP 28013-602 Campos dos Goytacazes (RJ). E-mail: ldobbss@uenf.br

(3) Professor Adjunto, Departamento de Química, Universidade Federal Rural do Rio de Janeiro - UFRRJ. BR 465, Km 7 , CEP 23890-000 Seropédica (RJ). E-mail: rumjanek@ufrrj.br

(4) Pós-Doutorando, Laboratório de Solos, UENF. E-mail: marihus@uenf.br

(5) Professor Titular, Laboratório de Solos, UENF. E-mail : velloso@uenf.br

(6) Professor Associado, Laboratório de Solos, UENF. E-mail: canellas@uenf.br
} 
permitiu separar a maioria desses ácidos, indicando a presença de frações humificadas de natureza química individual.

Termos de indexação: matéria orgânica, espectroscopia, substâncias húmicas, solos tropicais.

\title{
SUMMARY: CHEMICAL AND SPECTROSCOPIC CHARACTERIZATION OF HUMIC AND FULVIC ACIDS ISOLATED FROM THE SURFACE LAYER OF BRAZILIAN OXISOLS
}

\begin{abstract}
The determination of structural characteristics of humic substances (HS) is essential to understand the behavior of surface chemistry of highly weathered soils. Humic acids (HA) and fulvic acids (FA) isolated from the surface horizon of seven Oxisols of different locations of Brazil were characterized by analyses of elemental composition, total and carboxylic acidity, oxidation capacity and spectroscopic techniques. The oxidation degree of the humic substances was high, while acidity and molecular weight were relatively low, indicating a very reactive alkaline soluble organic matter. Compared with HA, the C content of FA was lower and oxygen content higher. The $E_{4} / E_{6}$ ratio values were high and the molar mass was estimated at 1.106 and $618 \mathrm{~g} \mathrm{~mol}^{-1}$ for HA and FA, respectively. The lower molar mass observed for FA was consistent with the lower chemical complexity detected by Fourier-transform infrared spectroscopy (FT-IR), showing fewer well-defined spectral bands. The results of ${ }^{1} \mathrm{H}$-nuclear magnetic resonance (H-NMR) spectroscopy indicated more hydrophobic H in HA and a high amount of $H$ bonded with $O$ in $F A$, consistent with the higher acidity and solubility at any $p H$ value. Despite the similar chemical functionality found, both HA and FA, most humic substances could be distinguished by the principal component analysis, indicating distinct chemical attributes of the humic fractions.
\end{abstract}

Index terms: organic matter, spectroscopy, humic substances, tropical soils.

\section{INTRODUÇÃO}

O teor de matéria orgânica influencia o comportamento do solo, principalmente dos altamente intemperizados (Fontes et al., 2001). Os Latossolos constituem a principal classe desse tipo de solo no Brasil (Resende et al., 1997). São solos profundos, geralmente ácidos, com CTC baixa e dependente do pH e do comportamento das cargas da fração orgânica (Mendonça et al., 2006).

Apesar do progresso acelerado no estudo da química das substâncias húmicas (SH), há muitas indefinições e pouco consenso sobre o assunto. As SH têm sido descritas genericamente como macromoléculas orgânicas heterogêneas, de coloração escura, resultado do produto do metabolismo de microrganismos (Aiken et al., 1985). Piccolo (2002) aplicou o conceito da química das supramoléculas para $\mathrm{SH}$ e, por meio de uma série de evidências cromatográficas (Piccolo et al., 1996) e espectroscópicas (Simpson, 2002; Piccolo \& Spiteller, 2003), postulou uma nova concepção para a estrutura das SH. Moléculas orgânicas diversas, mas relativamente pequenas, formam agregados unidos entre si por ligações hidrogênio e interações hidrofóbicas fracas, formando um arranjamento supramolecular. Esse arranjamento apresenta massa molecular só aparentemente elevada, mas que pode ser constante e indefinidamente alterada de acordo com as variações nas condições do meio de reação. Nessa perspectiva, Piccolo (2002) redefiniu AF como produto da associação de moléculas pequenas e hidrofílicas com uma quantidade de grupos funcionais acídicos suficiente para manter os agregados dispersos a qualquer valor de $\mathrm{pH}$. Os ácidos húmicos $(\mathrm{AH})$, por sua vez, foram definidos como associações nas quais predominam compostos hidrofóbicos (cadeias polimetilênicas, ácidos graxos, esteróides) estabilizados $\mathrm{em} \mathrm{pH}$ neutro por forças hidrofóbicas dispersivas. A conformação dos $\mathrm{AH}$ cresce progressivamente de tamanho quando as forças oriundas das ligações hidrogênio são progressivamente aumentadas até um valor baixo de $\mathrm{pH}$ na qual floculam (Piccolo, 2002). De acordo com Sutton \& Sposito (2005), a nova concepção estrutural deve ganhar em precisão e acurácia com o desenvolvimento de ferramentas de automação e modelagem química.

As espectroscopias de UV-VIS e fluorescência, infravermelho (IV) e ressonância nuclear magnética (RMN) são bastante úteis na caracterização das SH. A espectroscopia na região de UV-VIS é usada, principalmente, para determinar a relação $\mathrm{E}_{4} / \mathrm{E}_{6}$ (razão entre a absorbância em $465 \mathrm{~nm}$ e $665 \mathrm{~nm}$, segundo Kononova, 1982). Os valores da relação $\mathrm{E}_{4} / \mathrm{E}_{6}$ apresentaram relação inversa com o progresso das reações de transformação das SH (Kononova, 1982), distribuição de massa molecular (Chen et al., 
1977) e quantidade de C-aromático (Saab \& MartinNeto, 2007). É possível também estimar a massa molar média pela absortividade na região entre 250 e $280 \mathrm{~nm}$ pela presença de uma absorção de pequena intensidade $\left(\varepsilon_{280}=204 \mathrm{~cm}^{2} \mathrm{~mol}^{-1}\right)$ devido à forte proibição quanto-mecânica. Essa absorção é fortemente afetada pela presença de grupos funcionais polares, como carbonilas, carboxilas e ésteres, que aumentam o $\varepsilon$ em relação à absortividade de anéis não substituídos, sendo possível relacionar linearmente a massa molar com a $\varepsilon_{280}$ (Ching et al., 1994; Peuravarouri \& Pihlaja, 2004). A espectroscopia de fluorescência vem sendo utilizada com sucesso para estabelecer grau de humificação das SH determinado pelo incremento de estruturas conjugadas com ressonância de elétrons, tais como anéis aromáticos e radicais livres do tipo semiquinonas (Martin-Neto et al., 1998; Milori et al., 2002). Grupos doadores de elétrons substitutos de compostos aromáticos, como carbonilas, hidroxilas, grupos amino, aumentam a intensidade de emissão de fluorescência para comprimentos de onda maiores (Senesi et al., 1991). Os radicais livres do tipo semiquinonas (RLS) participam das reações de transferência de elétrons (Struyk \& Sposito, 2001) e sua concentração geralmente é medida pela ressonância de elétrons (EPR). Baldotto (2006) verificou uma correlação estreita e significativa entre a concentração de RLS e a capacidade de oxidação (Cox) das SH medida por iodimetria, apresentando um procedimento acessível para estimativa da capacidade de transferência de elétrons das $\mathrm{SH}$.

Na região de IV é possível acessar a funcionalidade das SH, especialmente de grupos oxigenados, proteínas, polissacarídeos e proporção de grupos aromáticos/alifáticos e hidrofílicos/hidrofóbicos (Canellas et al., 2004). É possível também identificar uma "assinatura química" das SH a partir da análise da região entre 1.400 e $900 \mathrm{~cm}^{-1}$ conhecida como impressão digital (Colthup et al., 1964). A RMN é uma técnica versátil e bastante útil na análise estrutural de materiais complexos (Rumjaneck, 2005) e foi responsável, por exemplo, pela indicação inequívoca do comportamento supramolecular das $\mathrm{SH}$ (Simpson, 2002).

$\mathrm{O}$ objetivo deste trabalho foi caracterizar os $\mathrm{AH}$ e AF obtidos do horizonte superficial de sete diferentes Latossolos, por meio de métodos químicos e espectroscópicos.

\section{MATERIAL E MÉTODOS}

\section{Coleta e isolamento das substâncias húmicas}

Foram coletadas amostras do horizonte superficial de sete perfis diferentes de Latossolos previamente descritos em diferentes regiões do Brasil: Latossolo Amarelo eutrófico (LAe), Campos dos Goytacazes, RJ; Latossolo Bruno distroférrico (LBdf), Vacaria, RS;
Latossolo Vermelho perférrico (LVj), Nova Lima, MG; Latossolo Vermelho-Amarelo distrófico (LVAd), Nova Friburgo, RJ; Latossolo Vermelho acriférrico (LVwf), Santo Ângelo, RS; Latossolo Vermelho-Amarelo distroférrico (LVAdf), Mendes, RJ; Latossolo Vermelho distrófico (LVd), Brasília, DF. Os solos foram previamente estudados nas reuniões de correlação e classificação de solos (Embrapa, 1980, 1999) e nos trabalhos de Rodrigues \& Klant (1978), Anjos (1985) e Barreto (1986).

A extração da matéria húmica proveniente dos Latossolos estudados foi realizada com $\mathrm{NaOH}$ 0,1 $\mathrm{mol} \mathrm{L}^{-1}$, na razão solo:solvente de 1:10 (v:v) em atmosfera inerte de $\mathrm{N}_{2}$. A extração foi repetida até a obtenção de um extrato com absorbância igual a zero em 250 e $465 \mathrm{~nm}$. A separação dos AH foi conseguida com o abaixamento do $\mathrm{pH}$ da solução até $1,0 \mathrm{com} \mathrm{HCl}$ $6 \mathrm{~mol} \mathrm{~L}^{-1}$. A redissolução e precipitação foi repetida por três vezes. Em seguida, foram adicionados $200 \mathrm{~mL}$ de solução aquosa diluída de $\mathrm{HF}$ e $\mathrm{HCl}$ (preparada com $5 \mathrm{~mL}$ de $\mathrm{HCl}$ concentrado e $5 \mathrm{~mL}$ de $\mathrm{HF}$ concentrado e, o volume da solução completado para $1 \mathrm{~L}$ com água deionizada), agitando-se a amostra durante $8 \mathrm{~h}$. Os $\mathrm{AH}$ foram lavados com água deionizada até teste negativo para cloretos com $\mathrm{AgNO}_{3}$. Em seguida, os AH foram dializados contra água em membranas de "cut-off" de $14 \mathrm{kDa}$ e secos por liofilização. O sobrenadante produzido com a acidificação do meio alcalino foi colocado numa coluna preenchida com resina XAD-8 (36 g mL-1 de solução). A coluna foi lavada com dois volumes de água destilada e os AF, retidos na coluna, foram eluídos com uma solução de $\mathrm{NaOH} 0,1 \mathrm{~mol} \mathrm{~L}^{-1}$. Em seguida, a solução alcalina com AF foi eluída numa coluna preenchida com resina trocadora de cátions Amberlite IAR $120 \mathrm{H}^{+}$ e dializada contra água em membranas com poros de 700 Da e secos por liofilização.

\section{Caracterização das substâncias húmicas solúveis}

A composição elementar foi realizada em analisador automático Perkin Elmer 2.400, com amostras de $4 \mathrm{mg}$ de AH e de AF em duplicata: o teor de $\mathrm{O}$ foi determinado por diferença, descontados os teores de cinzas e de umidade obtidos com a análise termogravimétrica (dados não mostrados); a acidez total, pelo método do $\mathrm{Ba}(\mathrm{OH})_{2}$ com titulação do excesso de base com $\mathrm{HCl}$; a acidez carboxílica, pelo tratamento com $\mathrm{Ca}(\mathrm{OAc})_{2}$ e a determinação do Ac liberado foi realizada com $\mathrm{NaOH}$, e a fenólica, por diferença, p.ex., acidez total - carboxílica, de acordo com método de Schnitzer \& Gupta (1965).

A titulação redox das amostras de $\mathrm{AH}$ e $\mathrm{AF}$ foi realizada sob atmosfera de $\mathrm{Ar}$, numa suspensão aquosa em temperatura ambiente $\left(25^{\circ} \mathrm{C}\right)$, controlada por fluxo contínuo em banho MQBTC 99-20 ${ }^{\circledR}$, por meio da oxidação com $\mathrm{I}_{2}$. $\mathrm{O}$ ponto de equivalência da curva de titulação foi ajustado para $\mathrm{E}_{\mathrm{H}}(\mathrm{mV})$ em função da quantidade crescente de redutor no sistema $(\mu \mathrm{L}$ de $\mathrm{I}_{2}$ ). O ponto de inflexão da curva foi arbitrado como o 
calculado pela segunda derivada da equação ajustada com ajuda do software Origin ${ }^{\circledR}$ e que, aplicado à formula $\left[\mathrm{mol}_{\mathrm{c}} \mathrm{kg}^{-1}=\left(2 \mathrm{~mol}_{\mathrm{c}} / \mathrm{mol}_{\mathrm{c}} \mathrm{I}\right) \mathrm{x}\right.$ (molalidade solução $\mathrm{I}_{2} \mathrm{x}$ densidade solução $\mathrm{I}_{2}$ )/massa $\mathrm{AH}$ ou $\left.\mathrm{AF}\right]$, forneceu o número de moles de carga transferidos por unidade de massa de $\mathrm{AH}$ e $\mathrm{AF}\left(\mathrm{mol}_{\mathrm{c}} \mathrm{kg}^{-1}\right)$, definido como a capacidade de oxidação (Cox) de cada AH e AF (Baldotto, 2006).

A espectroscopia na região do infravermelho das $\mathrm{SH}$ solúveis foi realizada na faixa de $500 \mathrm{~cm}^{-1}$ a $4.000 \mathrm{~cm}^{-1}$, utilizando-se pastilhas com $1 \mathrm{mg}$ de SH solúveis em $100 \mathrm{mg}$ de $\mathrm{KBr}$, num aparelho Perkin Elmer 1420.

A intensidade de fluorescência foi obtida em solução aquosa de $\mathrm{AH}$ e $\mathrm{AF}$ na concentração de $50 \mathrm{mg} \mathrm{L}^{-1}$ equilibrada a $25^{\circ} \mathrm{C}$ e $\mathrm{pH}=8$. Utilizou-se um espectrofotômetro Hitachi F-4500, e as condições experimentais utilizadas foram as mesmas indicadas por Milori et al. (2002).

A massa molar média das SH foi estimada a partir da absortividade molar em $280 \mathrm{~nm}\left(\varepsilon_{280}\right)$ de acordo com o procedimento de Ching et al. (1994). Pela equação $\mathrm{MM}=3,99 \varepsilon_{280}+450$, foram obtidas correlações elevadas com a distribuição média da massa molecular das SH por cromatografia, por exclusão de tamanho ou por sedimentometria por ultracentrifugação, e com o grau de aromaticidade obtido por RMN (Ching et al., 1994).

Os espectros de $\mathrm{RMN}^{1} \mathrm{H}\left({ }^{1} \mathrm{H}: 300 \mathrm{MHz}\right)$ foram obtidos num aparelho Varian com probe de $5 \mathrm{~mm}$. As amostras foram dissolvidas em $0,7 \mathrm{~mL}$ de $\mathrm{NaOD} / \mathrm{D}_{2} \mathrm{O}$ $0,1 \mathrm{~mol} \mathrm{~L}^{-1}$, e o espectro foi obtido com a saturação do sinal de água. A varredura do espectro foi de $4.800 \mathrm{~Hz}$, e foram obtidos 64 scans por espectro com tempo de aquisição de $3,6 \mathrm{~s}$ e delay de $0,5 \mathrm{~s}$.

\section{Análise Estatística}

Foi empregada a técnica multivariada de componentes principais, cuja finalidade exploratória possibilita a verificação da maior ou menor sensibilidade das variáveis em questão (grau de humificação x $\mathrm{AH}$ e $\mathrm{AF}$ ) no que se diz respeito à separação dos Latossolos estudados. Em tal técnica, a primeira componente é descrita de forma que os pontos resultem na maior variabilidade possível entre todas as coordenadas lineares; e a segunda deve ter o máximo de variância igual ou menor que a primeira, sendo ortogonal a esta. Esta nova configuração de pontos é obtida pela determinação de autovetores a partir da matriz de variância (Gnanadesikan, 1977).

\section{RESULTADOS E DISCUSSÃO}

\section{Caracterização das substâncias húmicas solúveis}

As características das $\mathrm{SH}$ dependem dos fatores de formação do solo e são intensamente modificadas pela atividade antropogênica. O processo de latossolização é comum à classe de solo eleita para este estudo, e os perfis utilizados foram previamente indicados como perfis modais (Barreto, 1986). Procurou-se diversidade entre os Latossolos (Quadro 1) para a caracterização das $\mathrm{SH}$.

A composição elementar, livre de umidade e cinzas, e as relações atômicas dos $\mathrm{AH}$ e $\mathrm{AF}$ são mostradas no quadro 1 . Os resultados da acidez, relação $\mathrm{E}_{4} / \mathrm{E}_{6}$, fluorescência, capacidade de oxidação e estimativa da massa molar média (MM) são mostrados no quadro 2. De modo geral, pode-se observar que o teor de $\mathrm{C}$ nas $\mathrm{SH}$ isoladas dos diferentes Latossolos é baixo e o de $\mathrm{O}$ é elevado em relação à média de outros $\mathrm{AH}$ e $\mathrm{AF}$ descritos na literatura (Rice \& MaCarthy, 1991).

$\mathrm{O}$ teor de $\mathrm{C}$ nos $\mathrm{AH}$ variou de 432 a $563 \mathrm{~g} \mathrm{~kg}^{-1} \mathrm{e}$ nos $\mathrm{AF}$ de 261 a $612 \mathrm{~g} \mathrm{~kg}^{-1}$. Já o teor de $\mathrm{O}$ variou de 505 a $667 \mathrm{~g} \mathrm{~kg}^{-1}$ nos AH e numa faixa maior, entre 519 e $877 \mathrm{~g} \mathrm{~kg}^{-1}$ nos AF. O teor médio mais elevado de $\mathrm{C}$ nos $\mathrm{AH}$ e menor de $\mathrm{O}$ é compatível com o maior grau de humificação dos $\mathrm{AH}$ em relação aos $\mathrm{AF}$ (Stevenson, 1994). O teor de N encontrado foi elevado, entre 47 e $69 \mathrm{~g} \mathrm{~kg}^{-1}$ nos AH e entre 50 e $100 \mathrm{~g} \mathrm{~kg}^{-1}$ nos

Quadro 1. Composição elementar livre de umidade e cinzas e relações atômicas de ácidos húmicos e fúlvicos isolados de sete Latossolos brasileiros

\begin{tabular}{|c|c|c|c|c|c|c|c|}
\hline Latossolos $^{(1)}$ & C & $\mathbf{H}$ & $\mathbf{N}$ & $\mathrm{O}$ & $\mathrm{C} / \mathrm{N}$ & $\mathrm{H} / \mathrm{C}$ & $\mathrm{O} / \mathrm{C}$ \\
\hline & \multicolumn{5}{|c|}{$-\mathrm{g} \mathrm{kg}^{-1}$} & - & \\
\hline & \multicolumn{7}{|c|}{ Ácidos Húmicos } \\
\hline LAe & 562,5 & 64,0 & 52,5 & 558,7 & 12,5 & 1,4 & 0,7 \\
\hline LBdf & 542,0 & 64,1 & 58,9 & 524,1 & 10,7 & 1,4 & 0,7 \\
\hline $\mathrm{LVj}$ & 503,1 & 51,1 & 49,9 & 627,5 & 11,8 & 1,2 & 0,9 \\
\hline LVAd & 432,0 & 56,6 & 57,8 & 667,2 & 8,7 & 1,6 & 1,2 \\
\hline LVwf & 468,0 & 60,9 & 46,6 & 603,7 & 11,7 & 1,6 & 1,0 \\
\hline LVAdf & 504,8 & 61,1 & 68,5 & 504,6 & 8,6 & 1,5 & 0,7 \\
\hline $\mathrm{LVd}$ & 536,5 & 62,7 & 52,9 & 542,7 & 11,8 & 1,0 & 0,8 \\
\hline Média & 507,0 & 60,1 & 55,3 & 575,5 & 10,8 & 1,4 & 0,9 \\
\hline \multirow[t]{2}{*}{$\mathrm{DP}$} & 45,3 & 4,7 & 7,2 & 59,1 & 1,6 & 0,1 & 0,2 \\
\hline & \multicolumn{7}{|c|}{ Ácidos Fúlvicos } \\
\hline LAe & 545,1 & 67,7 & 87,6 & 519,1 & 7,3 & 1,5 & 0,7 \\
\hline LBdf & 303,0 & 55,4 & 64,4 & 843,0 & 5,5 & 2,2 & 2,1 \\
\hline $\mathrm{LVj}$ & 301,7 & 64,3 & 99,7 & 867,6 & 3,5 & 2,6 & 2,2 \\
\hline LVAd & 611,6 & 73,8 & 95,7 & 689,4 & 7,5 & 1,5 & 0,8 \\
\hline LVwf & 261,2 & 46,1 & 50,0 & 877,2 & 6,1 & 2,1 & 2,5 \\
\hline LVAdf & 342,8 & 46,5 & 63,3 & 797,4 & 6,3 & 1,6 & 1,7 \\
\hline LVd & 515,1 & 70,8 & 91,9 & 655,5 & 6,5 & 1,7 & 1,0 \\
\hline Média & 411,5 & 60,7 & 79,0 & 749,9 & 6,1 & 1,9 & 1,6 \\
\hline $\mathrm{DP}$ & 141,3 & 11,4 & 19,4 & 133,4 & 1,3 & 0,4 & 0,7 \\
\hline
\end{tabular}

(1) LAe: Latossolo Amarelo eutrófico; LBdf: Latossolo Bruno distroférrico; LVj: Latossolo Vermelho perférrico; LVAd: Latossolo Vermelho-Amarelo distrófico; LVwf: Latossolo Vermelho acriférrico; LVAdf: Latossolo Vermelho-Amarelo distroférrico; LVd: Latossolo Vermelho distrófico. ${ }^{(2)} \mathrm{DP}$ : desvio-padrão. 
Quadro 2. Acidez total, carboxílica e fenólica (obtida por diferença), relação $\mathrm{E}_{4} / \mathrm{E}_{6}$, intensidade de fluorescência, capacidade de oxidação e massa molar média de ácidos húmicos e fúlvicos isolados de sete Latossolos brasileiros

\begin{tabular}{|c|c|c|c|c|c|c|c|c|}
\hline Latossolos & $\mathrm{COOH}$ & OH fenólico & Acidez total & $\mathbf{E}_{4} / \mathbf{E}_{6}$ & $\operatorname{IF}^{(1)}$ & $\operatorname{Cox}^{(2)} \mathrm{pH}_{5}$ & $\operatorname{Cox} \mathbf{p H}_{7}$ & $\operatorname{MMr}^{(3)}$ \\
\hline & 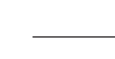 & $-\mathrm{cmol} \mathrm{kg}^{-1}$ & - & - & u.a & $-\mathrm{mol}_{\mathrm{c}}$ & $\mathrm{g}^{-1}-$ & $\mathrm{g} \mathrm{mol}^{-1} \mathrm{C}^{-1}$ \\
\hline \multicolumn{9}{|c|}{ Ácidos Húmicos } \\
\hline LAe & 264,4 & $1.301,0$ & $1.565,4$ & 7,2 & 107,3 & 1,0 & 1,5 & 990 \\
\hline LBdf & 197,4 & $1.230,0$ & $1.427,4$ & 6,9 & 158,5 & 1,1 & 1,9 & 1.100 \\
\hline $\mathrm{LVj}$ & 70,8 & $1.909,8$ & $1.980,4$ & 6,7 & 80,7 & 1,9 & 2,9 & 990 \\
\hline LVAd & 184,6 & $1.210,8$ & $1.395,4$ & 4,0 & 149,6 & 1,5 & 2,7 & 1.227 \\
\hline LVwf & 69,4 & $1.495,0$ & $1.564,4$ & 6,5 & 81,7 & 1,3 & 2,4 & 1.227 \\
\hline LVAdf & 354,5 & 942,0 & $1.296,5$ & 5,4 & 115,1 & 2,3 & 3,5 & 1.163 \\
\hline $\mathrm{LVd}$ & 223,6 & $1.513,6$ & $1.737,1$ & 8,9 & 113,6 & 1,1 & 1,7 & 1.045 \\
\hline Média & 194,9 & $1.371,7$ & $1.566,7$ & 6,5 & 115,2 & 1,5 & 2,4 & 1.106 \\
\hline $\mathrm{DP}$ & 102,0 & 305,6 & 231,7 & 1,5 & 30,1 & 0,5 & 0,7 & 102,6 \\
\hline \multicolumn{9}{|c|}{ Ácidos Fúlvicos } \\
\hline LAe & 168,3 & $1.754,4$ & $1.922,6$ & 9,5 & 28,1 & 0,5 & 1,0 & 524 \\
\hline LBdf & 245,5 & $2.061,3$ & $2.306,8$ & 13,2 & 15,5 & 0,9 & 1,6 & 887 \\
\hline $\mathrm{LVj}$ & 357,1 & $2.193,8$ & $2.551,0$ & 11,8 & 36,0 & 0,5 & 1,5 & 507 \\
\hline LVAd & 314,3 & $1.654,4$ & $1.968,7$ & 9,3 & 30,6 & 0,8 & 2,1 & 794 \\
\hline LVwf & 267,9 & $1.598,4$ & $1.866,3$ & 10,8 & 40,4 & 1,3 & 2,5 & 534 \\
\hline LVAdf & 163,6 & $1.813,6$ & $1.977,2$ & 9,3 & 42,0 & 1,0 & 2,2 & 557 \\
\hline $\mathrm{LVd}$ & 229,2 & $1.109,4$ & $1.338,6$ & 10,0 & 19,5 & 1,0 & 1,5 & 524 \\
\hline Média & 249,4 & $1.740,8$ & $1.990,2$ & 10,5 & 30,3 & 0,9 & 1,8 & 618 \\
\hline $\mathrm{DP}$ & 71,4 & 351,2 & 378,6 & 1,5 & 10,1 & 0,3 & 0,5 & 155,0 \\
\hline
\end{tabular}

COOH: acidez carboxílica; OH fenólico: acidez fenólica; DP: desvio-padrão.

(1) Intensidade total de fluorescência em unidades arbitrárias (u.a) obtida pelo espectro de emissão de uma solução de AH e AF (20 mg L ${ }^{-1}$ de C) com excitação fixa em $456 \mathrm{~nm} .{ }^{(2)}$ Cox: Capacidade de oxidação. ${ }^{(3)}$ MMr: massa molar média obtida pela equação $\mathrm{y}=3,99 \varepsilon+490$ no qual $\varepsilon$ é a absortividade molar em $280 \mathrm{~nm}$ com concentração em moles de $20 \mathrm{mg} \mathrm{L}^{-1}$ de $\mathrm{C}_{\mathrm{AH}}$ ou $\mathrm{C}_{\mathrm{AF}}$.

AF, indicando que as $\mathrm{SH}$ servem como uma importante fonte de compostos nitrogenados armazenados nos diferentes Latossolos. Curtin \& Wen (1999) verificaram que as frações solúveis de matéria orgânica foram significativamente correlacionadas com o Nmineralizável do solo, e Jacquin \& Vong (1989) identificaram os AF como a principal fração alcalina solúvel responsável pela estabilização de $\mathrm{N}$ adicionado na forma de $\left({ }^{15} \mathrm{NH}_{4}\right)_{2} \mathrm{SO}_{4}$.

$\mathrm{O}$ teor elevado de $\mathrm{N}$ e baixo de $\mathrm{C}$ nos $\mathrm{AH}$ e $\mathrm{AF}$ confere às $\mathrm{SH}$ uma baixa relação $\mathrm{C} / \mathrm{N}$. Trabalhos anteriores como os de Kumada (1965) e Stevenson (1994) concebiam a humificação como um processo de aumento de condensação química (união de moléculas com eliminação de água) das unidades estruturais mediados geralmente por grupos nitrogenados. Portanto, a incorporação ou os teores elevados de N foram considerados como um atributo de materiais bastante humificados. Neste trabalho, verificou-se um teor elevado tanto de $\mathrm{N}$ como de $\mathrm{O}$, além de teores baixos de $\mathrm{C}$ indicando um processo bastante particular de estabilização de material húmico com possível presença de substâncias húmicas de baixa massa molecular na fração solúvel. Os AH dos Latossolos apresentaram uma relação $\mathrm{C} / \mathrm{N}$ média de 11 e os $\mathrm{AF}$ apresentam valores ainda menores (próximos de 6). Valores excepcionalmente baixos da relação $\mathrm{C} / \mathrm{N}$ foram encontrados nos AF isolados do LVj 3,5 aproximadamente, que pode ser associado mais à involução química das SH do que estabilização pela atividade biológica. É possível que a mineralogia predominada por óxidos de ferro impeça a evolução das $\mathrm{SH}$, gerando baixo acúmulo de $\mathrm{C}$ e complexação de formas de $\mathrm{N}$ em reações com $\mathrm{OH}$ fenólicos. A relação $\mathrm{O} / \mathrm{C}$ é 0,7 vez maior nos $\mathrm{AF}$ do que nos $\mathrm{AH}$, confirmando a maior acidez desses compostos, o que permite sua solubilidade em qualquer valor de $\mathrm{pH}$ do meio.

Foi encontrada maior acidez total nos AF que apresentam, em média, $1.990 \mathrm{cmol}_{\mathrm{c}} \mathrm{kg}^{-1}$ com valores oscilando entre 2.551 e $1.339 \mathrm{cmol}_{\mathrm{c}} \mathrm{kg}^{-1}$ entre os Latossolos. Os AH apresentam média elevada de acidez total $\left(1.567 \mathrm{cmol}_{\mathrm{c}} \mathrm{kg}^{-1}\right)$ com valores oscilando entre 1.980 e $1.296 \mathrm{cmol}_{\mathrm{c}} \mathrm{kg}^{-1}$. A acidez total dos AF foi 1,27 vez maior do que a dos $\mathrm{AH}$, um indicativo da maior hidrofilicidade dos AF. A acidez total das SH é alta e está de acordo com o grau elevado de oxidação e, 
portanto, com o elevado teor de O. Essa elevada reatividade indica uma participação significativa das SH no desenvolvimento de cargas nos Latossolos. A acidez fenólica foi responsável por quase dois terços do $\mathrm{H}^{+}$na acidez total das $\mathrm{SH}$. Como o $\mathrm{pKa}$ aparente desses grupamentos é bem mais elevado do que o dos grupos $\mathrm{CO}_{2} \mathrm{H}$, na faixa de $\mathrm{pH}$ normalmente encontrada para os Latossolos, a carga líquida negativa é praticamente devida à dissociação de $\mathrm{CO}_{2} \mathrm{H}$ que aparece em menor proporção na acidez total.

Os AH isolados do LVj e do LVwf apresentaram valores mais baixos de acidez carboxílica $(70,75 \mathrm{e}$ $69,44 \mathrm{cmol}_{\mathrm{c}} \mathrm{kg}^{-1}$, respectivamente) em relação aos AH isolados dos demais Latossolos. Os teores de hematita e goethita, no primeiro solo, e de $\mathrm{Al}^{3+}$, no segundo, aumentam a possibilidade de formação de complexos estáveis com Fe e Al. Mendonça \& Rowell (1996) mostraram o bloqueio dos grupamentos funcionais oxigenados pela formação de complexos. Esse bloqueio pode diminuir a evolução química das $\mathrm{SH}$ promovendo acúmulo de $\mathrm{AF}$ ou de $\mathrm{AH}$ com baixo grau de humificação.

Os valores da relação $\mathrm{E}_{4} / \mathrm{E}_{6}$ variaram numa faixa muito ampla, com valor médio de 6,5 para $\mathrm{AH}$ e 10,5 para os $\mathrm{AF}$. Os valores de $\mathrm{E}_{4} / \mathrm{E}_{6}$ para os $\mathrm{AH}$ variaram de 4,0 para o $\mathrm{AH}$ isolado do LVAd e 8,9 para $\mathrm{AH}$ isolado de LVd. Já o maior valor de $\mathrm{E}_{4} / \mathrm{E}_{6}$ dos $\mathrm{AF}$ foi encontrado no $\mathrm{AF}$ isolado do LBdf e os menores nos LVAd e LVAdf (9,3 para ambos). Essa relação foi utilizada para caracterizar as $\mathrm{SH}$ em vários tipos de ambientes por Kononova (1982). Foi observado anteriormente por cromatografia que os valores dessa relação decresciam com o aumento da complexidade e heterogeneidade das amostras de $\mathrm{SH}$, indicando que esse atributo poderia ser utilizado para estimar o grau de humificação (Kononova, 1982).

Os valores da relação em solos naturalmente férteis, de clima temperado, são menores do que 5 para $\mathrm{AH}$ e entre 6 e 8,5 para AF (Stevenson, 1994), valores bem abaixo da faixa observada para as $\mathrm{SH}$ dos Latossolos estudados. É possível então indicar menor grau relativo de complexidade química das SH dos Latossolos em relação aos solos de regiões de clima temperado. Chen et al. (1977) verificaram que a relação $\mathrm{E}_{4} / \mathrm{E}_{6}$ é governada, principalmente, pela massa molecular, uma vez que o fenômeno do espalhamento da luz no comprimento de onda do visível é fortemente influenciado pela massa molecular tanto quanto a presença de cromóforos. Esses autores observaram uma correlação inversa e significativa entre $\mathrm{E}_{4} / \mathrm{E}_{6}$ e a massa molecular média determinada por cromatografia de exclusão ou por ultracentrifugação. Sendo assim, é possível propor que os agregados húmicos compostos pelos $\mathrm{AH}$ apresentam tamanho relativamente maior do que os formados pelos $\mathrm{AF}$ e que esses são bem menores do que os observados para SH de clima temperado.

Adicionalmente, foi realizada, neste estudo, a estimativa da massa molar média das SH solúveis, utilizando-se a equação de Ching et al. (1994) validada pelo estudo de Peuravarouri \& Pihlaja (2004). Os valores absolutos da massa molar média obtidas dessa forma podem ser usados para uma comparação relativa entre as substâncias obtidas com mesmo procedimento experimental. Foram encontrados valores entre 990 e $1.227 \mathrm{~g} \mathrm{~mol}^{-1} \mathrm{de}_{\mathrm{AH}}$ e de $507 \mathrm{e}$ $887 \mathrm{~g} \mathrm{~mol}^{-1}$ de $\mathrm{C}_{\mathrm{AF}}$, respectivamente, ou seja, um incremento médio de $63 \%$ no tamanho do agregado húmico em relação ao agregado fúlvico. Essa distribuição média da massa molar relativamente pequena para as SH dos Latossolos é compatível com os valores elevados de acidez total, carboxílica e fenólica, da relação $\mathrm{E}_{4} / \mathrm{E}_{6}$ e com o baixo teor de $\mathrm{C}$ e elevado de $\mathrm{O}$ encontrados anteriormente.

As figuras 1 e 2 apresentam os espectros de IV-TF dos $\mathrm{AH}$ e $\mathrm{AF}$ isolados dos Latossolos estudados, respectivamente. Os espectros apresentaram perfil típico de ácidos orgânicos fracos e polipróticos (Colthup et al., 1964). De modo geral, os espectros de AH apresentam nove bandas de absorção bem definidas e comum a todos: uma banda de absorção intensa, forte e larga com centro em $3.380 \mathrm{~cm}^{-1}$ (variando de 3.346 a $3.396 \mathrm{~cm}^{-1}$ ) devido ao estiramento de ligações $\mathrm{O}-\mathrm{H}$ de vários grupos hidroxilados, mas principalmente ácidos carboxílicos capazes de fazer ligações hidrogênio que alteram a frequência de estiramento provocando o alargamento da banda de absorção; uma aguda e bem definida banda de absorção centrada em $2.929 \mathrm{~cm}^{-1}$ devido ao estiramento simétrico de ligações C-H, principalmente de grupos metil $\left(\mathrm{CH}_{3}\right)$; banda de absorção forte e larga com centro em $1.716 \mathrm{~cm}^{-1}$ (variando entre $1.722 \mathrm{~cm}^{-1}$ e $1.712 \mathrm{~cm}^{-1}$ ), atribuída genericamente à presença de carbonilas $(\mathrm{C}=\mathrm{O})$ em cetonas e aldeídos; uma banda de absorção intensa e alargada em $1.634 \mathrm{~cm}^{-1}\left(1.625\right.$ e $\left.1.635 \mathrm{~cm}^{-1}\right)$ atribuída à presença de uma série de estiramento simétricos de ligações $\mathrm{C}=\mathrm{O}$ de grupos $\mathrm{COO}^{-}$, banda de Amida II e quinonas; banda de absorção centrada em $1.533 \mathrm{~cm}^{-1}$, devido a estiramentos C-C de anéis aromáticos (indicador da presença de ligninas) e sistemas $\mathrm{N}=\mathrm{C}$ conjugados; uma banda de absorção em $1.447 \mathrm{~cm}^{-1}$ atribuída à deformação de ligações $\mathrm{C}$-H de grupos metil e metilenos; uma banda de absorção bem definida centrada em $1.249 \mathrm{~cm}^{-1}$ atribuída à presença de deformação de $\mathrm{O}-\mathrm{H}$ em grupos carboxílicos e ligações éster (C-O) e ainda à presença de fenóis; uma banda de absorção centrada em $1.126 \mathrm{~cm}^{-1}$ e $1.035 \mathrm{~cm}^{-1}$ devida a estiramentos $\mathrm{C}-\mathrm{O}$ de polissacarídeos nos $\mathrm{AH}$. Por fim, as bandas de absorção entre 800 e $900 \mathrm{~cm}^{-1}$ atribuídas a vibrações de ligações C-H de grupos aromáticos e de impurezas inorgânicas e organometálicas.

As principais diferenças entre os $\mathrm{AH}$ residem na intensidade da banda de absorção atribuída a $\mathrm{CH}_{3}$ (mais intensa nos AH LBdf, LAe e LVAdf, com aparecimento de uma absorção adicional em $2.840 \mathrm{~cm}^{-1}$ atribuída a $\mathrm{C}-\mathrm{H}$ de metilenos) e no alargamento da banda de absorção em $1.634 \mathrm{~cm}^{-1}$ nos AH isolados do LBdf e LVAd. A análise da região de impressão digital 
(entre 1.400-900 $\mathrm{cm}^{-1}$ ) revela uma similaridade muito grande na funcionalidade dos espectros de IV, mas que, no entanto, não são exatamente idênticos, indicando uma gênese distinta para cada $\mathrm{AH}$ nos sete Latossolos estudados.
Os espectros de IV dos AF são compatíveis com a maior homogeneidade estrutural desse conjunto de agregados húmicos, apresentando-se de forma mais simplificada, com absorções mais agudas e com sensíveis diferenças entre os tipos de AF. É comum a
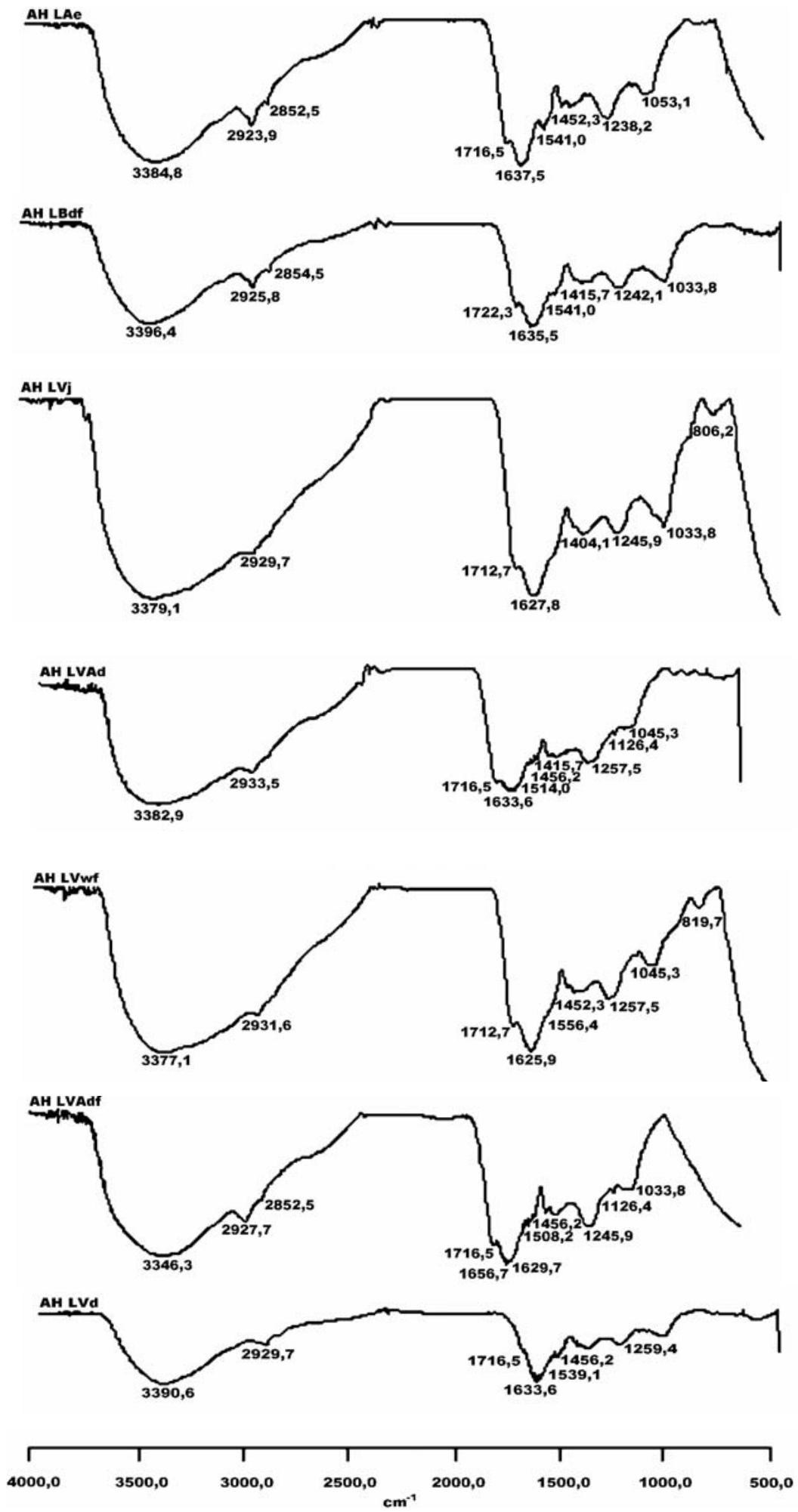

Figura 1. Espectros na região de infravermelho obtidos com transformada de Fourier de ácidos húmicos (AH) isolados do horizonte superficial dos sete Latossolos brasileiros. 

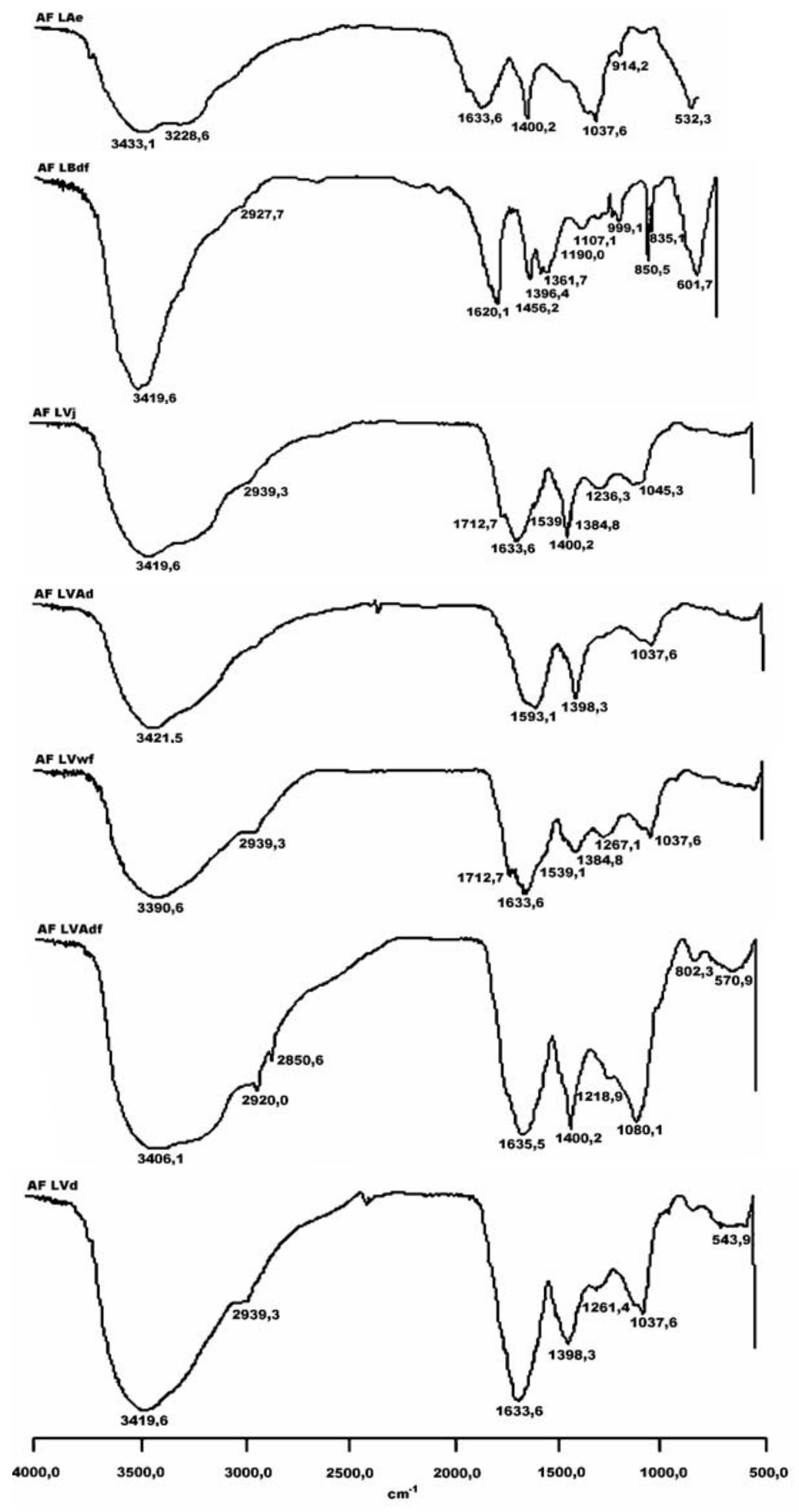

Figura 2. Espectros na região de infravermelho obtidos com transformada de Fourier de ácidos fúlvicos (AF) isolados do horizonte superficial dos sete Latossolos brasileiros.

todos os AF a banda de absorção centrada em $3.419 \mathrm{~cm}^{-1}$, atribuída a estiramentos $\mathrm{O}-\mathrm{H}$, mais alargada nos $\mathrm{AF}$ isolados do LVAdf, LVj e LAe, que apresentaram um ombro adicional em $3.228 \mathrm{~cm}^{-1}$. Essa banda de absorção centrada em $3.400 \mathrm{~cm}^{-1}$ é bem mais estreita no $\mathrm{AF}$ isolado do LBdf, indicando baixo grau de associação dessas SH. Os AF isolados do LVj, LVwf e $\mathrm{LVd}$ apresentaram ombro de absorção em $2.940 \mathrm{~cm}^{-1}$ atribuído a estiramento $\mathrm{C}-\mathrm{H}$ de metilas.

A intensidade de emissão de fluorescência com excitação fixa em $465 \mathrm{~nm}\left(\mathrm{IF}_{465}\right)$ foi maior nos $\mathrm{AH}$ comparada aos AF. Entre os diferentes AH, os isolados 
do LBdf e do LVAd tiveram quase o dobro da $\mathrm{IF}_{465}$ do que os $\mathrm{AH}$ isolados do LVj e do LVwf. Os AH isolados do LVd, LVAdf e LAe apresentam $\mathrm{IF}_{465}$ intermediária entre os extremos citados. Os AF isolados de LBdf e LVd apresentam uma intensidade muito baixa de emissão de fluorescência, enquanto os AF isolados de LVwf e LVAdf apresentam uma intensidade relativamente maior. $\mathrm{A} \mathrm{IF}_{465}$ pode ser usada com objetivo de discriminar as SH (Senesi et al., 1991) e estabelecer uma ordem relativa ao grau de humificação entre os AH e AF estudados. Milori et al. (2002) obtiveram correlações significativas entre a $\mathrm{IF}_{465}$ e a concentração de radicais do tipo semiquinonas e com o grau de aromaticidade obtido por $\mathrm{RMN}{ }^{13} \mathrm{C}$ em $\mathrm{AH}$ de diferentes fontes. $\mathrm{O}$ interesse dessa correlação, de acordo com Milori et al. (2002), vem da possibilidade de interpretação da teoria da humificação no sentido de identificar um aumento do grau de maturidade das SH com a estabilização de estruturas conjugadas com ressonância de elétrons, tais como anéis aromáticos e radicais livres do tipo semiquinonas que aumentam de concentração com a evolução química das SH (Zech et al., 1997). Dessa forma, SH mais humificadas devem apresentar, relativamente, maior intensidade de emissão de fluorescência com excitação no azul (Senesi et al., 1991). Segundo o índice $\mathrm{IF}_{465}$, o grau de humificação dos AH apresenta a ordem: $\mathrm{LBdf}=\mathrm{LVAd}$ $>\mathrm{LVd}=\mathrm{LVAdf}>\mathrm{LAe}>\mathrm{LVwf}=\mathrm{LVj}$, e a dos AF a seguinte: $\mathrm{LVAdf}=\mathrm{LVwf}>\mathrm{LVj}>\mathrm{LVAd}=\mathrm{LAe}>\mathrm{LVd}$ $>$ LBdf.

A capacidade de oxidação das SH determinada a pH $7\left(\mathrm{Cox}_{7}\right)$ está associada à presença de elétrons disponíveis para reações de oxirredução, importantes na complexação de íons, principalmente Fe (Struyk $\&$ Sposito, 2001). A capacidade de transferir um $\operatorname{mol}_{c}$ para uma unidade de massa de um agente oxidante forte (capacidade de oxidação, Cox) pode avaliar indiretamente o grau de humificação das $\mathrm{SH}$, uma vez que a quantidade de elétrons está relacionada à presença de radicais livres do tipo semiquinona (Baldotto, 2006). A Cox definiu assim o poder redutor das SH, que foi compatível com o seu grau de evolução química (Baldotto et al., 2005). A Cox em $\mathrm{pH} 7$ variou de 1,51 a 3,48 mol $_{c} \mathrm{~kg}^{-1}$ para $\mathrm{AH}$ e 1,04 a 2,45 mol $_{\mathrm{c}} \mathrm{kg}^{-1}$ para os AF.

Os espectros de $\mathrm{RMN}^{1} \mathrm{H}$ de $\mathrm{AH}$ e $\mathrm{AF}$ isolados dos Latossolos são apresentados na figura 3 e resultado da integração das principais regiões de deslocamento químico $\left(\delta_{\mathrm{H}}\right)$ dos respectivos espectros, mostrados no quadro 3. Os espectros foram divididos em três regiões principais de $\delta_{\mathrm{H}}$. A primeira região entre $0,2 \mathrm{e}$ $3,0 \mathrm{~Hz} \mathrm{MHz}^{-1}$ é geralmente assinalada como a de $\mathrm{H}$ alifáticos, enquanto o final dessa faixa do espectro, entre 2,0 e $2,8 \mathrm{~Hz} \mathrm{MHz}^{-1}$, pode ser atribuído a $\mathrm{H}$ ligados a átomos eletronegativos $(\mathrm{O}$ e $\mathrm{N}) . \mathrm{O} \delta_{\mathrm{H}}$ entre 0,9 e $1,3 \mathrm{~Hz} \mathrm{MHz}^{-1}$ pode ser atribuído à existência de $\mathrm{H}$ em grupos metilas de cadeias alifáticas ramificadas ou grupos metilas em posição terminal em longas cadeias metilênicas. A segunda região é compreendida pelos $\delta_{\mathrm{H}}$ entre 3 e $4,5 \mathrm{~Hz} \mathrm{MHz}^{-1}$ e atribuída a $\mathrm{H}$ ligados a $\mathrm{C} \alpha$ ligados a $\mathrm{O}$ e no caso de $\mathrm{SH}$ genericamente atribuídos à presença de polissacarídeos. A terceira região, entre 6 e $8,5 \mathrm{~Hz} \mathrm{MHz}^{-1}$, é em virtude da presença de $\mathrm{H}$ em anéis aromáticos. $\mathrm{Os} \mathrm{AH}$ apresentam um conteúdo bem mais elevado de $\mathrm{H} \mathrm{em}$ cadeias alifáticas hidrofóbicas do tipo metila e metileno com $\delta_{\mathrm{H}}$ entre 0 e $2 \mathrm{~Hz} \mathrm{MHz}^{-1}$ do que os $\mathrm{AF}$. Além disso, os $\mathrm{AH}$ apresentam em média um teor de $\mathrm{H}$ na região de compostos aromáticos de $17 \%$, enquanto nos AF esse valor é de $11 \%$. Os AF apresentaram menor quantidade de $\mathrm{H}$ em grupos metilas $\left(\mathrm{CH}_{3}\right)$ e metilenos $\left(\mathrm{CH}_{2}\right)$ do que os $\mathrm{AH}$ e, além disso, a quantidade relativa de $\mathrm{CH}_{2}$ foi maior do que a de $\mathrm{CH}_{3}$ nos espectros dos $\mathrm{AF}$.

Outra diferença significativa com relação à distribuição de $\mathrm{H}$ nos $\mathrm{AF}$ em relação aos $\mathrm{AH}$ corresponde a maior quantidade de $\mathrm{H}$ na região de $\delta_{\mathrm{H}}$, entre 3 e $4,5 \mathrm{~Hz} \mathrm{MHz}^{-1}$ que, corresponde genericamente à região de $\mathrm{H}-\mathrm{C}-\mathrm{O}, \mathrm{CH}-\mathrm{C}=\mathrm{O}$, e de olefinas (duplas ligações). Essa região correspondeu, em média, a $44 \%$ dos $\mathrm{H}$ nos $\mathrm{AF}$ e a $33 \%$ nos $\mathrm{AH}$. Essa maior quantidade de $\mathrm{H}$ ligadas a $\mathrm{O}$ está de acordo com a maior acidez total dos AF. O grau de aromaticidade dos $\mathrm{AH}$ decresce na ordem: $\mathrm{LAe}=\mathrm{LVd}$ $>\mathrm{LVj}>\mathrm{LBdf}=\mathrm{LVwf}=\mathrm{LVAdf}>\mathrm{LVAd}$, e o de hidrofobicidade na ordem: LVwf $>$ LBdf $>$ LVAd $>$

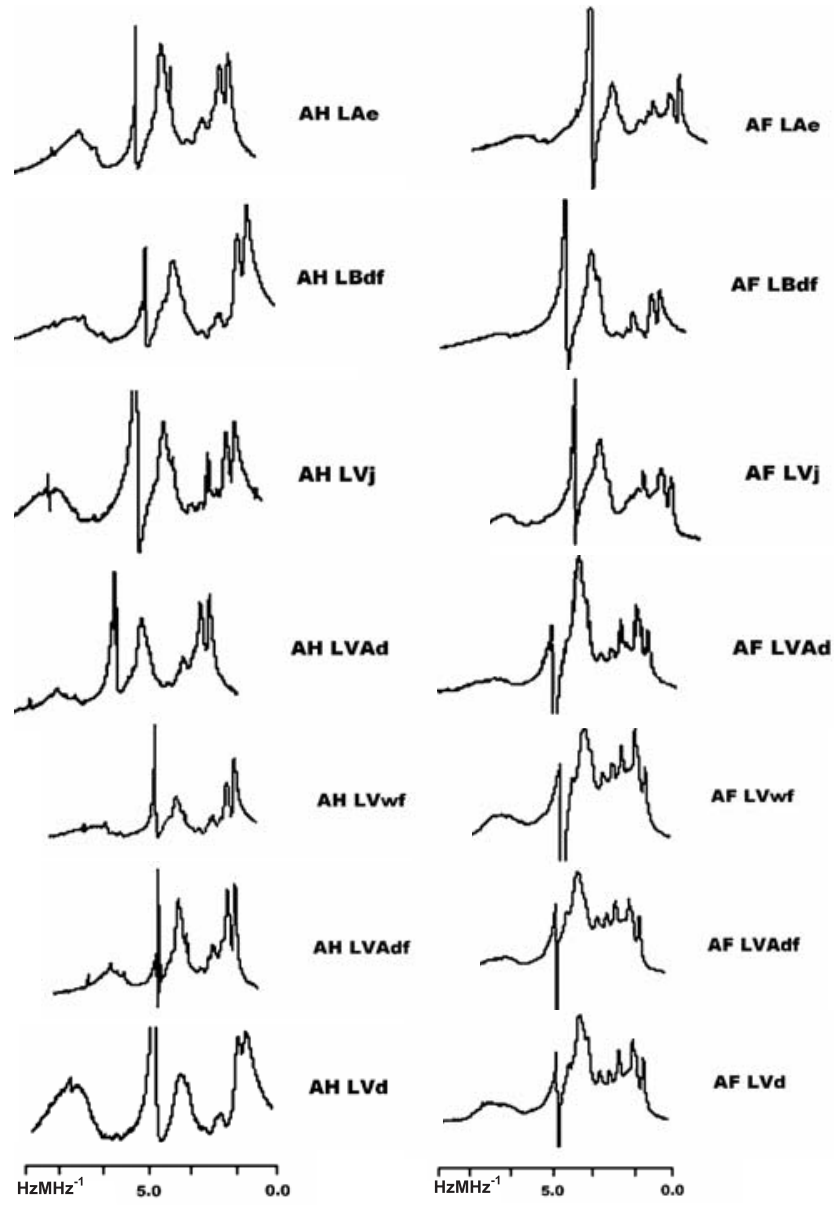

Figura 3. Espectros de $\mathrm{RMN} \mathrm{H}^{1}$ de ácidos húmicos (AH) e fúlvicos (AF) do horizonte superficial dos sete Latossolos brasileiros 
Quadro 3. Distribuição relativa dos deslocamentos químicos ( $\delta$ ) de hidrogênio em $\mathrm{Hz} \mathrm{MHz}^{-1}$ obtidos por ressonância magnética nuclear $(\mathrm{RMN})$ de ácidos húmicos (AH) e fúlvicos (AF) de sete Latossolos brasileiros estudados

\begin{tabular}{|c|c|c|c|}
\hline \multirow[t]{2}{*}{ Latossolos $^{(1)}$} & $\mathrm{H}$ alifático & \multicolumn{2}{|c|}{$\mathrm{H}$ polissacarídeo $\mathrm{H}$ aromático } \\
\hline & $0,2-3,0$ & $3,0-4,5$ & $6,0-8,5$ \\
\hline & & $\%$ & - \\
\hline & & Ácidos Húmicos & \\
\hline LAe & 45 & 34 & 21 \\
\hline LBdf & 54 & 30 & 16 \\
\hline $\mathrm{LVj}$ & 47 & 35 & 18 \\
\hline LVAd & 53 & 35 & 12 \\
\hline LVwf & 55 & 29 & 15 \\
\hline LVAdf & 47 & 39 & 14 \\
\hline $\mathrm{LVd}$ & 52 & 27 & 21 \\
\hline Média & 50 & 33 & 17 \\
\hline \multirow[t]{2}{*}{$\mathrm{DP}$} & 4,0 & 4,2 & 3,5 \\
\hline & & Ácidos Fúlvicos & \\
\hline LAe & 53 & 30 & 16 \\
\hline LBdf & 42 & 46 & 12 \\
\hline $\mathrm{LVj}$ & 46 & 40 & 14 \\
\hline LVAd & 42 & 50 & 8 \\
\hline LVwf & 46 & 42 & 12 \\
\hline LVAdf & 49 & 47 & 5 \\
\hline LVd & 40 & 51 & 9 \\
\hline Média & 45 & 44 & 11 \\
\hline $\mathrm{DP}$ & 4,5 & 7,2 & 3,8 \\
\hline
\end{tabular}

(1) LAe: Latossolo Amarelo eutrófico; LBdf: Latossolo Bruno distroférrico; LVj: Latossolo Vermelho perférrico; LVAd: Latossolo Vermelho-Amarelo distrófico; LVwf: Latossolo Vermelho acriférrico; LVAdf: Latossolo Vermelho-Amarelo distroférrico; LVd: Latossolo Vermelho distrófico. DP: desviopadrão.
$\mathrm{LVd}>\mathrm{LVj}=\mathrm{LVAdf}>\mathrm{LAe}$. Já para os AF, o grau de aromaticidade decresce na seguinte ordem: $\mathrm{LAe}>\mathrm{LVj}$ $>$ LBdf $=$ LVwf $>$ LVd $>$ LVAd $>$ LVAdf, e o de hidrofobicidade na sequência a seguir: LAe > LVAdf $>\mathrm{LVwf}=\mathrm{LVj}>\mathrm{LVAd}=\mathrm{LBdf}>\mathrm{LVd}$. A aplicação da RMN ${ }^{1} \mathrm{H}$ permitiu observar que os $\mathrm{AH}$ são mais hidrofóbicos, menos ácidos e com conteúdo maior de compostos aromáticos. Por outro lado, as principais absorções dos $\mathrm{AF}$ dizem respeito ao elevado conteúdo de grupamentos oxigenados $-\mathrm{COOH},-\mathrm{OCH}_{3},-\mathrm{C}=\mathrm{O}$ e $\mathrm{OH}$ de fenóis, originados de polissacarídeos de origem vegetal como ligninas e celulose. Foi possível, portanto, estabelecer um processo de humificação seletivo para as SH dos Latossolos, ou seja, o processo de humificação é bastante similar ao observado anteriormente por Zech et al. (1997), que viram uma diminuição na intensidade da região dos espectros de RMN atribuída a polissacarídeos e aumento relativo da intensidade da região de grupos alifáticos e aromáticos. Esta seqüência é comum ao processo de latossolização dos horizontes superficiais.

Foi usada a técnica de estatística multivariada para discriminar as SH usando os atributos químicos como grupos de variáveis. Os resultados obtidos da simulação feita neste trabalho foram decompostos em autovalores/autovetores. Esses autovalores forneceram a variância dos componentes principais. Observou-se que $87 \%$ da variância total foi representada pelos três primeiros componentes principais, podendo-se distinguir facilmente o grupo dos AH e dos AF (Figura 4). Os componentes principais, ao contrário das variáveis originais, não possuem significado físico, mas podem ser interpretados como uma combinação linear dessas variáveis originais. No caso mostrado na figura 4 , por exemplo, as variáveis originais de maior peso

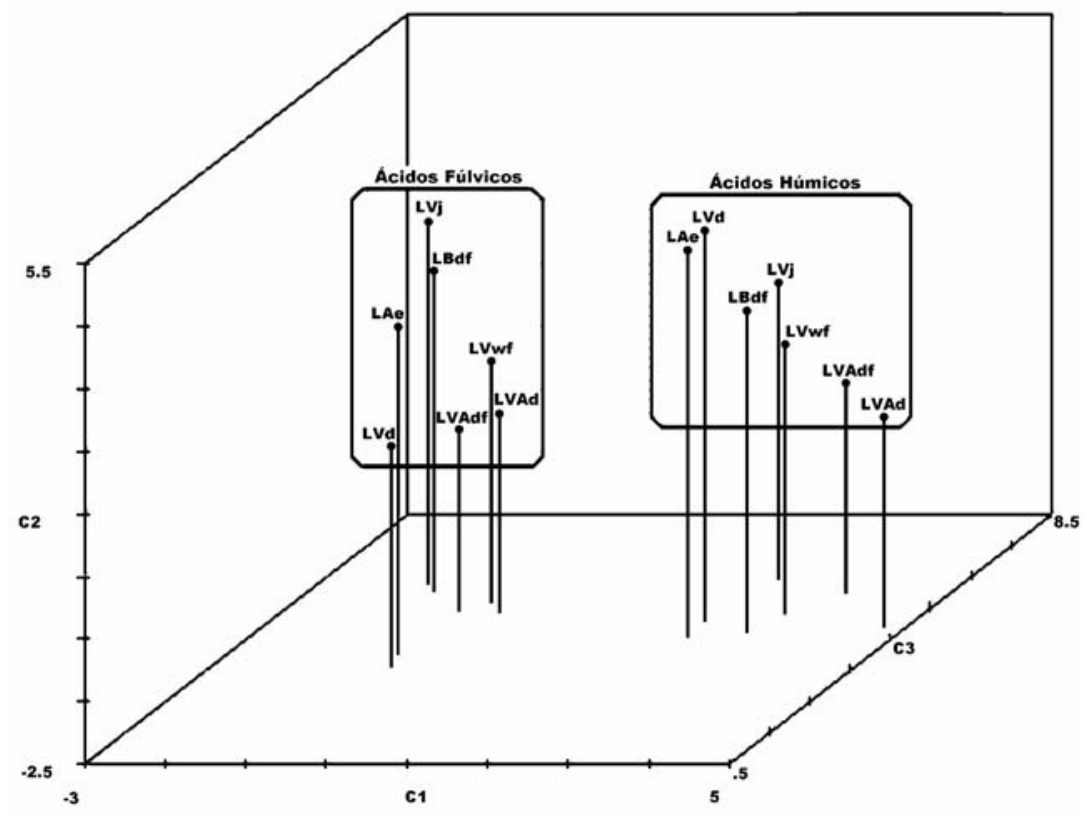

Figura 4. Análise de agrupamentos em componentes principais. 
foram: relação $\mathrm{E}_{4} / \mathrm{E}_{6}>$ relação atômica $\mathrm{C} / \mathrm{H}>$ relação atômica $\mathrm{O} / \mathrm{C}$.

A figura 5 apresenta os resultados da análise estatística gráfica utilizada com todos os atributos químicos analisados para discriminar ou agrupar os $\mathrm{AH}$ ou os AF, por meio da análise de componentes principais (ACP). Neste caso, a ACP foi usada para julgar a importância das próprias variáveis originais escolhidas, ou seja, as variáveis originais com maior peso foram as mais importantes no ponto de vista estatístico.

Para os AH foi possível observar 89 \% da variação nos primeiros três componentes. As variáveis de maior valor para discriminar os $\mathrm{AH}$ foram: aromaticidade por $\mathrm{RMN}>$ massa molar média $>$ relação $\mathrm{E}_{4} / \mathrm{E}_{6}$. Foi possível observar claramente que, apesar da similaridade funcional entre os $\mathrm{AH}$, há uma nítida distinção entre os diferentes Latossolos, evidenciando uma identidade química particular para cada $\mathrm{AH}$ (Figura 5a). Já para os AF, observaram-se $86 \%$ da variação nos três primeiros componentes, e as variáveis de maior poder de discriminação foram: o
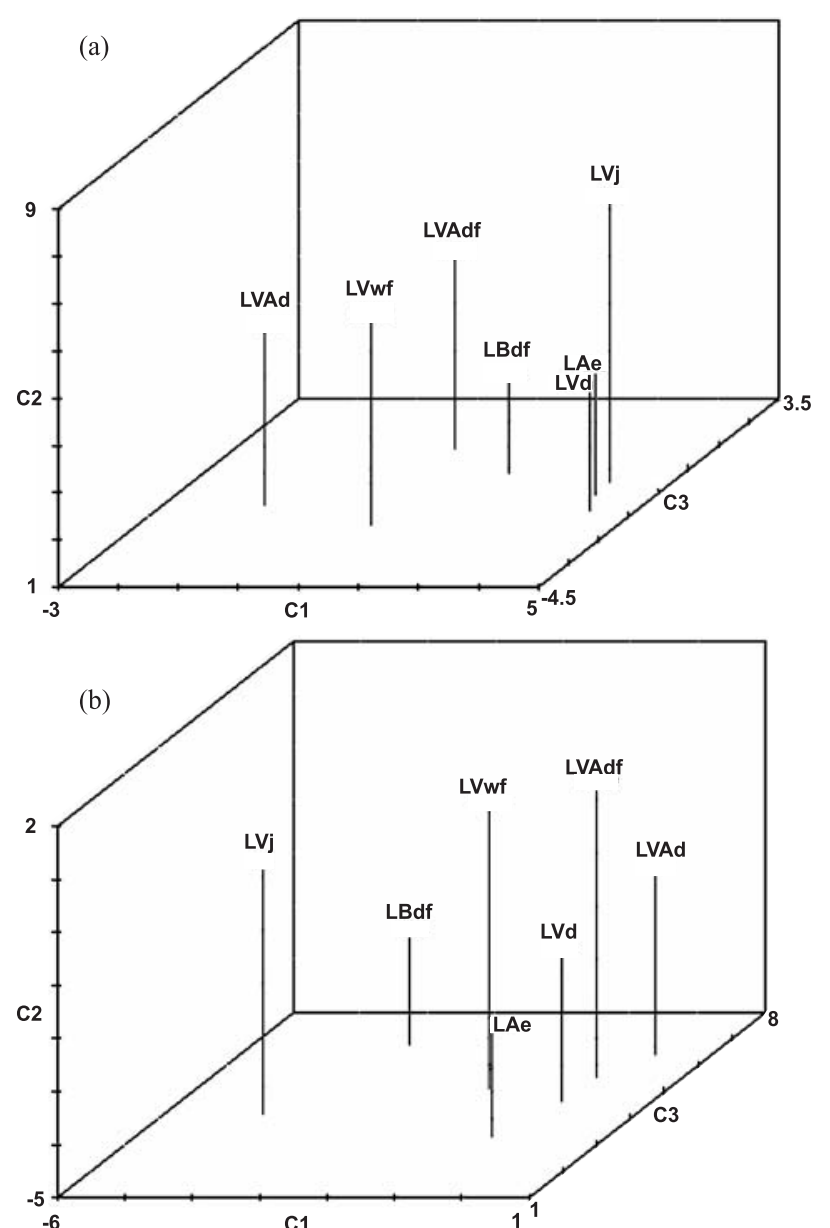

Figura 5. Dispersão (a) dos ácidos húmicos e (b) dos ácidos fúlvicos isolados dos Latossolos em relação aos seus escores, nos três primeiros componentes principais. índice de fluorescência (IF), a relação $\mathrm{E}_{4} / \mathrm{E}_{6}$, e a relação atômica $\mathrm{O} / \mathrm{C}$, respectivamente. Assim como os $\mathrm{AH}$, foi possível observar que os AF possuem uma clara similaridade funcional, porém também se distinguem pela ACP (Figura 4b).

\section{CONCLUSÕES}

1. As análises químicas e espectroscópicas dos AH e AF permitiram concluir que estes compostos possuem características estruturais diferenciadas.

2. Os AF apresentaram menor teor de $\mathrm{C}$, maior de $\mathrm{O}$ e de grupos ácidos e menor número de bandas de absorção bem definidas na região do IV, além de mais baixas relação $\mathrm{E}_{4} / \mathrm{E}_{6}$, massa molar média, intensidade de fluorescência com excitação fixa em $465 \mathrm{~nm}$, capacidade de oxidação, grau de aromaticidade e hidrofobicidade do que os AH.

3. Os dados da composição elementar, acidez e atividade redox das substâncias húmicas foram confirmados pelas análises espectroscópicas, indicando que a gênese das $\mathrm{SH}$ pode ser agrupada utilizando-se atributos químicos como grupos de variáveis.

4. A ACP permitiu obter uma identidade química particular tanto para os AH quanto para os AF. Foi possível distinguir facilmente, pela análise de agrupamentos, o grupo dos $\mathrm{AH}$ e dos $\mathrm{AF}$.

\section{AGRADECIMENTOS}

Este trabalho foi financiado pelo $\mathrm{CNPq}$, processo número 4813/2004-9, concedido ao prof. Ary Carlos Xavier Velloso. Os autores agradecem à professora Maria Cristina Canela pela colaboração na determinação da capacidade de oxidação.

\section{LITERATURA CITADA}

AIKEN, G.R.; McKNIGHT, D.M.; WERSHAW, R.L. \& MAcCARTHY, P. Introductory remarks. In: AIKEN, G.R.; MCKNIGHT, D.M.; WERSHAW R.L. \& MACCARTHY, P., eds. Humic substances in soil, sediment and waters. New York, Jonh Wiley, 1985. p.1-12.

ANJOS, L.H.C. Caracterização, gênese, classificação e aptidão agrícola de uma seqüência de solos do Terciário na região de Campos, RJ. Itaguaí, Universidade Federal Rural do Rio de Janeiro, 1985. 110p. (Tese de Mestrado)

BALDOTTO, M.A.; CANELLAS, L.P.; CANELA, M.C. \& VELLOSO, A.C.X. Propriedades redox das substâncias húmicas. In: CANELLAS, L.P. \& SANTOS, G.A., eds. Humosfera: Tratado preliminar sobre a química das substâncias húmicas. Campos dos Goytacazes, 2005. p.201-223. 
BALDOTTO, M.A. Propriedades redox e grupos funcionais de ácidos húmicos. em produção vegetal. Campos dos Goytacazes, UENF, 2006. 100p. (Tese de Doutorado)

BARRETO, W.O. Eletroquímica de solos tropicais de carga variável: Capacidade da dupla camada elétrica. Itaguaí, Universidade Federal Rural do Rio de Janeiro, 1986. 294p. (Tese de Doutorado)

CANELLAS, L.P.; ESPINDOLA, J.A.; REZENDE, C.E.; CAMARGO, P.B.; ZANDONADI, J.A.A.; RUMJANEK, V.M.; GUERRA, J.G.M.; TEIXEIRA, M.G. \& BRAZFILHO, R. Organic matter quality in a soil cultivated with perennial herbaceous legumes. Sci. Agric., 61:5361, 2004.

CHEN, Y., SENESI, N. \& SCHNITZER, M. Information provided on humic substances by $\mathrm{E}_{4} / \mathrm{E}_{6}$ rations. Soil Sci. Soc. Am. J., 41:352-358, 1977.

CHING, Y.P.; AIKEN, G. \& O'LOUGHLIN, E. Molecular weight, polidispersity, and spectroscopic properties of aquatic humic substances. Environ. Sci. Technol., 28:18531858,1994

COLTHUP, N.B.; DALY, L.H. \& WIBERLEY, S.E. Introduction to infrared and Raman spectroscopy. New York, Academic Press, 1964. 510p.

CURTIN, D. \& WEN, G. Organic matter fractions contributing to soil nitrogen mineralization potential. Soil Sci. Soc. Am. J., 63:410-415, 1999.

EMPRESA BRASILEIRA DE PESQUISA AGROPECUÁRIA EMBRAPA. Centro Nacional de Pesquisa do Solo. Levantamento e classificação de solos. Rio de Janeiro, Produção de Informação, 1980. (Boletim, 62)

EMPRESA BRASILEIRA DE PESQUISA AGROPECUÁRIA EMBRAPA. Centro Nacional de Pesquisa do Solo. Sistema brasileiro de classificação de solos. Rio de Janeiro, Produção de Informação, 1999. 412p.

FONTES, M.P.F., CAMARGO, O.A. \& SPOSITO, G. Eletroquímica das partículas coloidais e sua relação com a mineralogia de solos altamente intemperizados. Sci. Agric., 58:627-646, 2001.

GNANADESIKAN, R. Methods for statistical data analysis of multivariate observations. New York, Jonh Wiley \& Sons, 1977. $299 \mathrm{p}$

JACQUIN, F. \& VONG, P.G. Incorporation of nitrogen fertilizer in the humified compounds of a typic Hapludalf. Sci. Total Environ., 81/82:465-469, 1989.

KONONOVA, M.M. Matéria orgânica del suelo: Su naturaleza, propriedades y métodos de investigación. Barcelona, Oikos-Tou, 1982. 365p.

KUMADA K. Studies on the colour of humic acids. Part 1. On the concepts of humic substances and humification. Soil Sci. Plant Nutr., 11:11-16, 1965.

MARTIN-NETO, L.; ROSELL, R. \& SPOSITO, G. Correlation of spectroscopic indicators of humification with mean annual rainfall along a temperate grassland climosequence. Geoderma, 81:305-311, 1998.
MENDONÇA, E.S. \& ROWELL, D.L. Mineral and organic fractions of two oxisols and their influence on effective cation-exchange capacity. Sci. Soc. Am. J., 60:1888-1892, 1996.

MENDONÇA, E.S.; ROWELL, D.L.; MARTINS, A.G. \& SILVA, A.P. Effect of $\mathrm{pH}$ on the development of acidic sites in clayey and sandy loam Oxisol from the Cerrado Region, Brazil. Geoderma, 132:131-142, 2006.

MILORI, D.M.B.P.; MARTIN NETO, L.; BAYER, C.; MIELNICZUCK, J. \& BAGNATO, V.S. Humification degree of soil humic acids determined by fluorescence spectroscopy. Soil Sci., 167:739-749, 2002.

PEURAVAROURI, J. \& PIHLAJA, K. Preliminary estudy of lake dissolved organic matter in light of nanoscale supramolecular assembly. Environ. Sci. Technol., 38:59585967, 2004.

PICCOLO, A.; NARDI, S. \& CANCHERI, G. Macromolecular changes of soil humic substances induced by interactions with organic acids. Eur. J. Soil Sci., 47:319328,1996

PICCOLO, A. The Supramolecular structure of humic substances: A novel understanding of humus chemistry and implications in soil science. Adv. Agron., 75:57-134, 2002 .

PICCOLO, A. \& SPITELLER, M. Electrospray ionization mass spectrometry of terrestrial humic substances and their size fractions. Anal. Bioanal. Chem., 377:1047-1059, 2003.

RESENDE, M.; CURI, N.; REZENDE, S.B. \& CORRÊA, G.F. Pedologia: Base para a distinção de ambientes. Viçosa, MG, NEPUT, 1997. 367p.

RICE, J.A. \& MaCARTHY, P. Statistical evaluation of the elemental composition of humic substances. Org. Geochem., 17:635-648, 1991.

RODRIGUES, T.E. \& KLANT, E. Mineralogia e gênese de uma seqüência de solos do Distrito Federal. R. Bras. Ci. Solo, 2:132-139, 1978.

RUMJANECK, V.M. Ressonância magnética nuclear. In: CANELLAS, L.P. \& SANTOS, G.A. eds. Humosfera: Tratado preliminar sobre a química das substâncias húmicas. Campos dos Goytacazes, 2005.p.160-184.

SAAB, S.C. \& MARTIN-NETO, L. Anéis aromáticos condensados e relação $\mathrm{E}_{4} / \mathrm{E}_{6}$ : Estudo de ácidos húmicos de gleissolos por RMN de ${ }^{13} \mathrm{C}$ no estado sólido utilizando a técnica CP/MAS desacoplamento defasado. Quimica Nova, 30:260-263, 2007.

SCHNITZER, M. \& GUPTA, U.C. Determination of acidity in soil organic matter. Soil Sci. Am. Soc. Proc., 29:274-277, 1965 .

SENESI N.; MIANO, T.M.; PROVENZANO, M.R. \& BRUNETTI, G. Characterization, differentiation and classification of humic substances by fluorescence spectroscopy. Soil Sci., 152:259-271, 1991. 
SIMPSON, A.J. Determining the molecular weight, aggregation, structures and interactions of natural organica matter using diffusion ordered spectroscopy. Magnetic Res. Chem., 40:572-582, 2002.

STEVENSON, J.F. Humus chemistry: Genesis, composition, reactions. 2.ed. New York, John Wiley \& Sons, 1994. 496p.

STRUYK, Z. \& SPOSITO, G. Redox properties of standard humic acids. Geoderma, 102:329-346, 2001.
SUTTON, R. \& SPOSITO, G. Molecular structure in soil humic substances: The new view. Environ. Sci. Technol., 39:9009-9015, 2005.

ZECH, W.; SENESI, N.; GUGGENBERGER, G.; KAISER, K.; LEHMANN, J.; MIANO, T.M., MILTNER, A. \& SCHROTH, G. Factors controling humification and mineralizatino of soil organic matter in the tropics. Geoderma, 79:117-161, 1997. 